\title{
PENGARUH MEDIA SOSIAL BERBASIS WEB 4.0 TERHADAP MANAJEMEN PRIVASI KOMUNIKASI
}

\author{
Nadya Kartika Lumban Tobing ${ }^{1}$ \\ ${ }^{1}$ Departemen Ilmu Komunikasi, Fakultas Ilmu Sosial dan Ilmu Politik, Universitas Indonesia Jakarta \\ Email: nadya.kartika.27@gmail,com
}

Masuk : 13-06-2020, revisi: 23-01-2021, diterima untuk diterbitkan : 04-02-2021

\begin{abstract}
Technological development like social media has been affecting the openness of communication privacy management of its users. As a result of web development from web 2.0 to web 4.0, social media has gone through changes starting with the operational aspect of the applications, the distribution of information in the form of texts, images, and videos, the relation of interaction among users, to the relation between users and the engine of the applications (symbiotic web). The engine recommends users to work based on the results of how the users' personal data is processed, and by implication affects social media users' personal data management. Pervasive computing (easy access and connecting devices anywhere and anytime), symbiotic web (symbiotic relationships of people and devices), emotive web (emotional feelings), and ubiquitous computing (computers are everywhere) become part of web-based social media 4.0. The purpose of this study was to find out what factors of the four web 4.0-based social media concepts that most influence the privacy management of social media users' communications. This research method uses quantitative approach and survey method on 324 respondents taken through saturated samples. The result of this study is a significant influence on web-based social media 4.0 on the privacy management of social media users' communications. The concept of emotive web becomes the most influential variable towards the changes in communication privacy management.
\end{abstract}

Keywords: Social media, web 4.0, communication management privacy, social media users' private data

\section{ABSTRAK}

Perkembangan teknologi seperti media sosial telah memengaruhi keterbukaan manajemen privasi komunikasi penggunanya. Perkembangan dari web 2.0 hingga web 4.0, media sosial mengalami perubahan mulai dari operasional aplikasi, distribusi informasi dari teks, gambar, dan video, hubungan interaksi antara sesama pengguna, hingga hubungan pengguna dengan mesin aplikasi (symbiotic web). Mesin memberi rekomendasi kepada pengguna untuk bekerja berdasarkan pengolahan data diri pengguna dan secara tidak langsung telah memengaruhi pengelolaan data pribadi pengguna media sosial. Pervasive computing (memudahkan akses dan menghubungkan perangkat dimana saja dan kapan saja), symbiotic web (hubungan simbiosis manusia dan perangkat), emotive web (perasaan emosi), dan ubiquitous computing (komputer berada dimana saja) menjadi bagian dari media sosial berbasis web 4.0. Tujuan penelitian ini adalah untuk mengetahui faktor apa saja dari keempat konsep media sosial berbasis web 4.0 yang paling memengaruhi manajemen privasi komunikasi pengguna media sosial. Metode penelitian ini menggunakan pendekatan kuantitatif dan metode survei terhadap 324 responden yang diambil melalui sampel jenuh. Hasil penelitian ini adalah adanya pengaruh signifikan pada media sosial berbasis web 4.0 terhadap manajemen privasi komunikasi pengguna media sosial. Konsep emotive web, yaitu konsep yang membuat pengguna media sosial dapat membagikan emosi mereka secara daring menjadi variabel yang sangat berpengaruh terhadap perubahan manajemen privasi komunikasi.

Kata Kunci: Media sosial, web 4.0, manajemen privasi komunikasi, data privasi pengguna media sosial

\section{PENDAHULUAN}

\section{Latar Belakang}

Teknologi digital telah menjadi bagian dari kehidupan individu. Apalagi perkembangan saat ini, perangkat teknologi seperti telepon seluler (ponsel) seolah wajib dimiliki setiap individu. Interaksi antara mesin dan manusia terjalin secara simbiosis (symbiotic web), sebuah konsep besar dari web 4.0 (Choudhury, 2014). Berawal pada 1989, seorang ilmuwan komputer asal Inggris, Timothy Berners-Lee (1989) mengembangkan sebuah program yang disebut World Wide Web atau "www". Timothy menaruh harapan besar bahwa kehadiran web menjadi ruang untuk manusia saling berkomunikasi dan berbagi informasi, bersosialisasi, bermain, bekerja dengan baik dan semakin 
baik, serta menjadi tempat yang cocok untuk penggunanya (Nedeva \& Dineva, 2012). Kini, web telah berkembang pesat dan secara tidak langsung mempengaruhi budaya dan gaya komunikasi penggunanya.

Generasi pertama web 1.0 berkembang pada era 1990-an. Saat itu, pengguna web 1.0 masih pasif karena web berfungsi menampilkan informasi yang tersedia (read-only web). Lalu, masuklah web 2.0 yang telah menciptakan hubungan antara individu. Web 2.0 telah membangun konektivitas antara pengguna (interactivity and user participation) dan berkembangnya media sosial yang membuat penggunanya selalu aktif dalam jaringan internet. Pada tahap selanjutnya, web 3.0 menghadirkan sebuah konsep semantic web, web yang hadir sebagai penyedia informasi sesuai keperluan yang dicari oleh pengguna. Kini, telah berkembang web 4.0 yang dipandang sebagai web dengan jaringan cerdas (web of intelligence connections) (Polańska, 2014; Mulawarman \& Nurfitri, 2017; Almeida, 2018).

Meski berkembang pada era web 2.0, media sosial juga mengalami perubahan secara masif dari sisi teknologi. Media sosial berbasis web 4.0 mulai dijumpai dalam dunia digital. Dengan kemampuannya, media sosial berbasis web 4.0 diyakini tidak hanya diam dalam proses mengunggah data ke perangkat atau mesin, tetapi media sosial juga aktif mempelajari data dan secara otonom memproduksi konten (Almeida, 2018). Selain itu, perangkat media sosial berbasis web 4.0 tidak sebatas menyajikan informasi tetapi secara komprehensif dan persuasif mampu mengubah perilaku yang sesuai dengan apa yang dibutuhkan penggunanya (Patil \& Surwade, 2018). Media sosial berbasis web 4.0 menjadi agen pintar, perangkat ini memerlukan sumber data profil yang akurat untuk dapat menghasilkan preferensi yang optimal (Nedeva \& Dineva, 2012). Data dan profil ini dapat berupa teks, gambar, perkataan, ekspresi wajah, ataupun pengenalan suara. Sehingga media sosial berbasis web 4.0 sekaligus menjadi agen pribadi yang mengakses berbagai sistem yang dimiliki pengguna agar dapat menyusun profil dengan baik.

Salah satu bentuk keseriusan media sosial berbasis web 4.0 dalam mengoptimalkan layanan adalah dengan melakukan penghapusan akun atau avatar yang bersifat anonim. Seperti yang dilakukan media sosial Instagram pada 2014 saat menghapus jutaan akun sampah atau spam (BBC, 2014). Tujuannya untuk mencegah upaya memanfaatkan pengikut (followers) palsu untuk menjual popularitas demi keuntungan. Hal serupa dilakukan Facebook yang menghapus 753,7 juta akun di seluruh dunia dengan tujuan meminimalisir penyebaran berita bohong atau hoaks (Wardani, 2019). Adanya peristiwa ini menunjukkan bahwa media sosial berbasis web 4.0 mampu mengolah data dan membedakan akun anonim dan akun sesungguhnya. Hal ini mengindikasikan media sosial berbasis web 4.0 telah membangun sistem dalam memasukan data profil pengguna atau calon pengguna yang sesuai dengan data di dunia nyata.

Tingkat pertumbuhan pengguna media sosial di Indonesia mencapai 15\% dari tahun 2018 atau bertambah lebih dari 20 juta pengguna. Global Web Index (2019) menyebutkan bahwa individu memakan waktu hingga 3 jam 26 menit untuk bersosialisasi di ruang media sosial. Sementara kesadaran akan penyalahgunaan data privasi, baru menyentuh $49 \%$ dari total seluruh pengguna media sosial di Indonesia (We are Social, 2019). Artinya, ada setengah dari populasi pengguna media sosial di Indonesia yang tidak menyadari bahwa data mereka di dunia maya dapat disalahgunakan.

Data privasi dalam dunia digital telah menjadi salah satu masalah sejak perkembangan web 3.0 (Patil \& Surwade, 2018). Hal ini dinilai melanggar privasi dalam layanan internet, salah satunya dengan proses registrasi atau pengunggahan data pribadi. Padahal ini merupakan bagian dari 
fungsi semantic web yang bekerja untuk mengolah seluruh data agar menghasilkan konten dan produk yang optimal untuk pengguna. Kemudian kehadiran web 4.0 menegaskan proses pengolahan data pribadi menjadi bagian dalam membangun hubungan interaksi antara manusia dan mesin (symbiotic web) (Krumova, et al., 2017). Hubungan manusia dan mesin bertujuan untuk membangun kesan personal (Aghaei, et al., 2012). Hal ini mendorong privasi diri di dunia digital semakin kabur.

Kemampuan media sosial berbasis web 4.0 juga mengurangi keberadaan akun atau avatar yang anonimitas karena sifat web yang semakin personal (Polańska, 2014). Bahkan, beberapa media sosial menawarkan fungsi verifikasi akun untuk menentukan keaslian dari kepemilikan akun. Misalnya, Twitter dan Instagram yang menyediakan Lencana Akun Terverifikasi. Pengguna media sosial harus menyerahkan data privasi mereka untuk dapat memperoleh akses informasi dan fasilitas, seperti membuka akun Tokopedia, Bukalapak, Shopee, dan lainnya. Bahkan dengan berbasis web 4.0, media sosial dapat menganalisis sejumlah potensi produk atau konten yang menjadi preferensi penggunanya.

Media sosial berbasis web 4.0 seolah menjadi media untuk membagikan emosi pengguna secara daring melalui jaringan media sosial (Martínez-López et al., 2016). Disinilah privasi yang dinilai sebagai hak atas kontrol akses informasi pribadi berada pada tingkat risiko tinggi dalam jaringan internet (Petersons \& Khalimzoda, 2016). Privasi daring pun sulit dicapai karena informasi yang asimetri, kekuatan sosial dan politik, struktur yang tidak terlihat, teknolog komunikasi, serta perubahan kehidupan dan sumber daya (Barnard-Wills \& Ashenden, 2015).

Berbagai faktor dari luar diri individu ini dinilai menjadi salah satu penyebab pengguna media sosial berbasis web 4.0 akhirnya harus membuka data yang bersifat privasi. Kemampuan menyusun manajemen privasi dalam mempertimbangkan pengunggahan informasi pribadi telah dipengaruhi oleh konsep-konsep yang terdapat dalam web 4.0, yaitu pervasive computing, ubiquitous computing, symbiotic web, dan emotive web (Petronio, 2016). Berdasarkan berbagai pernyataan di atas dapat ditarik benang merah bahwa kehadiran media sosial berbasis web 4.0 mendorong keterbukaan data privasi bagi para pengguna media sosial.

\section{Media sosial di era web 4.0}

Media sosial berkembang pada masa web 2.0, lebih tepatnya web 2.5 pada 2005 (Almeida, 2018). Terjadi pergeseran akses dari desktop ke telepon seluler (ponsel) yang terhubung dengan internet, sehingga media sosial menjadi media yang selalu aktif. Media sosial digunakan pengguna untuk menggambarkan dirinya dan terhubung secara otomatis dengan pengguna lain. Kini, media sosia berbasis web 4.0 telah memantau perkembangan hubungan pengguna dengan media sosial (Mulawarman \& Nurfitri, 2017).

Ada tujuh klasifikasi dari media sosial, yaitu: (a) socialising - media penyedia ruang sosialisasi, misalnya Facebook dan Myspace; (b) professional - media sebagai penyedia forum profesional, misalnya Linkedin dan Profeo; (c) posting/publication - media sebagai tempat mempublikasikan konten pengguna, misalnya, Youtube dan Flickr; (d) microblogs - media sebagai ruang mengunggah teks pendek, misalnya, Twitter; (e) group shopping -media penyedia ruang transaksi produsen-konsumen, misalnya, Tokopedia dan Traveloka; (f) crowdfunding - media tempat mengumpulkan donasi, investasi, atau pinjaman, misalnya, KitaBisa.com dan Flatter; (f) wikimedia sebagai ruang membagikan dan mengedit konten, misalnya Wikipedia (Polańska, 2014; Kirik, et al., 2015). 
Media sosial berbasis web 4.0 melihat proses interaksi antara manusia dan komputer (Barnes \& Vidgen, 2003). Ada tiga area kajian media sosial berbasis web 4.0 menurut Sastika (2016), yaitu: (a) kualitas informasi - melihat keakuratan, kepercayaan, terbarukan, sesuai topik pembahasan, kemudahan dalam dimengerti, kelengkapan informasi, dan tampilan desain informasi yang sesuai kualitas informasi; (b) kualitas interaksi - dilihat dari kemampuan dalam memberi rasa aman ketika terjadi proses pertukaran, reputasi yang meyakinkan, kemudahan saat berkomunikasi, membangun perasaan personal dan penuh emosi, data privasi yang aman, membangun komunitas, memberikan kepercayaan atas implementasi nyata terhadap janji; (c) kualitas kegunaan - meliputi kemudahan media untuk dipelajari, dimengerti, ditelusuri, menarik, tampilan yang baik, menciptakan pengalaman baru yang menyenangkan. Tiga area ini dapat dilihat dalam empat konsep besar media sosial berbasis web 4.0, yaitu area kegunaan pada konsep pervasive computing, ubiquitous computing, area kualitas informasi pada konsep symbiotic web, dan area kualitas interaksi pada konsep emotive web.

Pervasive computing - teknologi terbaru yang dapat mengakses dan menghubungkan perangkat dimanapun dan kapan saja. Perangkat, jaringan, middleware, dan aplikasi menjadi empat bidang penting dalam konsep ini, untuk menciptakan saluran komunikasi yang aman sehingga membangun saluran kepercayaan dalam saluran nirkabel (Bhasker T, 2013). Pervasive computing melihat kegunaan seluruh perangkat media dalam operasionalisasi pada tingkat komunikasi yang tinggi, infrastruktur yang sejalan, aman, dan mudah dalam mengomunikasikan perangkat media (Almeida, 2018).

Ubiquitous computing - keberadaan komputer di mana-mana dan mampu secara aktif serta cerdas untuk berinteraksi dengan penggunanya (Weber \& Rech, 2010). Aplikasi dapat beradaptasi dengan dinamis sesuai kebutuhan dari pengguna, kemampuan perangkat, dan kondisi dari lingkungan, sehingga bekerja secara efisien dalam pengelolaan sumber data informasi (Artaza, 2012). Secara sederhana, mesin akan pandai membaca konten media sosial dan bereaksi dalam bentuk mengeksekusi dan memutuskan apa yang akan dieksekusi terlebih dahulu untuk memuat situs web atau aplikasi dengan cepat dengan kualitas dan kinerja yang unggul (Choudhury, 2014).

Symbiotic web - proses saat pikiran manusia dan mesin dapat berinteraksi dalam sebuah hubungan simbiosis (Ocampo, 2017). Terjadi perubahan dari intuitif menjadi integratif, sebuah konvergensi di berbagai tingkat, dari dalam jaringan (daring) dan luar jaringan (luring), virtual-nyata, dan digital-analog. Media sosial juga bekerja untuk mengingatkan pengguna hingga membangun banyak antarmuka yang memerintah (Aghaei et al., 2012).

Emotive web - pengguna membagikan emosinya secara daring melalui media sosial (MartínezLópez et al., 2016). Perangkat memungkinkan konten yang kaya akan visual hingga memungkinkan penggunanya mencapai perasaan puas dan kesuksesan tinggi. Media sosial menciptakan perolehan informasi yang kompleks di dunia internet, dengan meningkatkan integrasi pada waktu sebenarnya antara dunia maya dan manusia. Media sosial menciptakan personalisasi interaksi dan ikatan antara mesin dan manusia (Benito-Osorio et al., 2013). Media sosial sebagai mesin yang mampu menyaring informasi berdasarkan konteks, signifikansi, dan relevansi manusia. Hal ini menciptakan perbedaan informasi yang dihasilkan antara individu karena secara implisit reaksi individu yang berbeda-beda (Kurgun et al., 2018). Meski web yang netral tidak merasakan perasaan emosional penggunanya tetapi teknologi dinilai dapat mengukur efek yang ditimbulkan. Terdapat dalam lima dimensi yang memandang web dapat mengukur emosi individu, yaitu kesadaran emosional, regulasi emosional, otonomi emosional/ pengelolaan diri, kompetensi sosial, dan keterampilan hidup (Nisha \& Education, 2018). Emotive web telah menciptakan, 
teknologi neuro melalui ponsel yang memungkinkan pengguna untuk berinteraksi dengan konten yang memenuhi emosi atau mengubah ekspresi saat itu menjadi "avatar" (Patel, 2013).

\section{Teori manajemen privasi komunikasi}

Privasi dapat didefinisikan sebagai hak untuk mengontrol akses informasi pribadi, tetapi di sisi lain privasi menjadi masalah preferensi individu yang sulit dibenarkan secara umum (Moor, 1997). Terutama di era digital, privasi daring sulit dicapai karena informasi yang asimetri, kekuatan sosial dan politik, struktur yang tidak terlihat, teknologi, dan komunikasi, serta perubahan kehidupan dan sumber daya (Barnard-Wills \& Ashenden, 2015).

Teori manajemen privasi komunikasi fokus pada acara individu mendefinisikan dan mengomunikasikan informasi terkait pribadinya (Petersons \& Khalimzoda, 2016). Teori ini mencoba menjawab berbagai pertanyaan terkait hubungan antara pengungkapan dan privasi, penolakan atau pemberian ruang, pilihan untuk mengungkapkan dan menyembunyikan informasi, dan konsekuensi dari gangguan dalam manajemen privasi. Ada lima prinsip dan kriteria dari teori manajemen privasi komunikasi dalam membingkai privasi. Lima prinsip itu adalah (a) informasi diri; (b) permeability; (b) orang dalam/orang luar; (c) aturan privasi; dan (d) turbulensi. Sementara untuk lima kriteria terdapat (a) jenis kelamin; (b) budaya; (c) konteks; (d) motivasi; dan (e) risiko/manfaat (Petersons \& Khalimzoda, 2016)

Ada tiga prinsip dalam pengoperasian teori manajemen privasi komunikasi (Petersons \& Khalimzoda, 2016). Pertama, memahami kepemilikan informasi pribadi, sebagai hak individu mengambil keputusan untuk menunjukkan atau menyembunyikan akses pada orang lain. Informasi pribadi ini dapat diatur dalam dua jenis kriteria, yaitu inti (latar belakang) dan katalis (budaya). Kedua, kontrol informasi pribadi, melihat faktor budaya sebagai pemicu perubahan dalam aturan informasi privasi. Ketiga, turbulensi informasi pribadi saat manajemen privasi tidak lagi berfungsi. Hal ini melihat ketika individu terlibat sebuah dimensi sosial, maka manajemen privasi tidak berjalan sempurna.

Aspek penting dalam risiko privasi adalah siapa yang memiliki akses informasi pribadi pengguna yang dibagikan dalam jaringan sosial di internet. Informasi yang tersedia dalam jaringan, baik dalam waktu dan ruang, tidak sepenuhnya diketahui oleh pengguna media sosial (Tuunainen et al., 2009). Sejumlah masalah yang muncul terkait manajemen privasi terutama aplikasi media sosial yang memiliki potensial besar. Dalam hal ini penting untuk mempertimbangkan pihak lain dalam manajemen privasi, reaksi penerima dapat memengaruhi cara pemilik informasi itu mengelola informasi dirinya (Petronio, 2016).

\section{Rumusan Masalah}

Dalam penelitian sebelumnya, sejumlah penulis menuliskan berbagai prediksi terkait konsep web 4.0 dapat mempengaruhi manajemen privasi pengguna media dalam jaringan itu. Dalam jurnal berjudul Social Media in Modern Business karya Krystyna Polańska ia menuliskan bahwa akun anonimitas sangat tidak mungkin ada saat memasuki era web 4.0 (Polańska, 2014). Selain itu, penulis bernama Keshab Nath dan Raja Iswary dalam jurnal berjudul What Comes after Web 3.0? Web 4.0 and the Future juga mempertanyakan masalah privasi saat memasuki masa web 4.0 karena pencarian dapat bersifat personalisasi hanya dapat terjadi jika penggunanya memberikan data pribadi mereka pada mesin-mesin itu untuk diolah (Nath \& Iswary, 2015). Berangkat dari dua dasar pemikiran ini, penulis ingin membuktikan bahwa sejumlah konsep besar dari web 4.0 memang mendorong individu secara sadar atau tidak sadar untuk membuka data pribadi mereka melalui media sosial yang kerap digunakan sehari-hari. Berdasarkan pemikiran ini, penulis 
mengajukan rumusan masalah, yaitu "Faktor apa saja dalam media sosial berbasis web 4.0 yang mempengaruhi manajemen privasi penggunanya?"

\section{METODE PENELITIAN}

Untuk melihat pengaruh dari media sosial berbasis web 4.0 terhadap manajemen privasi individu, maka penelitian ini menggunakan pendekatan kuantitatif. Pendekatan ini dipilih karena penulis ingin melihat secara luar konsep pada web 4.0 di media sosial dapat memengaruhi manajemen privasi individu untuk membuka informasi pribadi di media sosial. Web 4.0 yang memiliki sejumlah konsep, diantaranya pervasive computing, ubiquitous computing, symbiotic web, dan emotive web dilihat sebagai faktor yang dapat memengaruhi keterbukaan informasi pribadi dalam media sosial.

Metode yang dipilih penulis adalah survei, karena penelitian ini hendak melihat sebuah isu dari perwakilan yang dapat merepresentasikan sebuah populasi (Neuman, 2014). Peneliti menggunakan teknik sampling nonprobabilitas karena kemudahan dalam menjangkau sampel yang tersedia dengan teknik sampling data jenuh. Pengambilan dengan teknik sampel data jenuh melihat sampel yang terkumpul mewakili populasi tersebut (Sugiyono, 2013). Dalam penelitian ini, populasi yang dituju adalah individu yang memiliki dan menggunakan media sosial. Dalam proses penyebaran lembaran kuesioner, penulis menggunakan fasilitas yang tersedia dari Google Form. Dari hasil sebaran tersebut, penulis mendapat 336 lembar survei yang kembali, tetapi penulis hanya mengolah 324 sampel karena sisanya tidak memenuhi persyaratan.

Teknik pengumpulan data dengan kuesioner akan menghasilkan sumber data primer dari responden yang menjadi sumber pertama (Neuman, 2014). Daftar pernyataan dalam kuesioner adalah jenis kuesioner tertutup, sehingga responden tinggal mengisi sesuai dengan jawaban yang paling sesuai. Sementara untuk alat pengukuran datanya, penulis memakai skala Likert untuk menentukan sikap responden (Neuman, 2014).

Dua instrumen penelitian adalah media sosial berbasis web 4.0 dan manajemen privasi komunikasi. Dua instrumen itu terdiri atas lima faktor yaitu pervasive computing, ubiquitous computing, symbiotic web, dan emotive web sebagai variabel $\mathrm{x}$, sementara manajemen privasi komunikasi sebagai variabel $\mathrm{y}$.

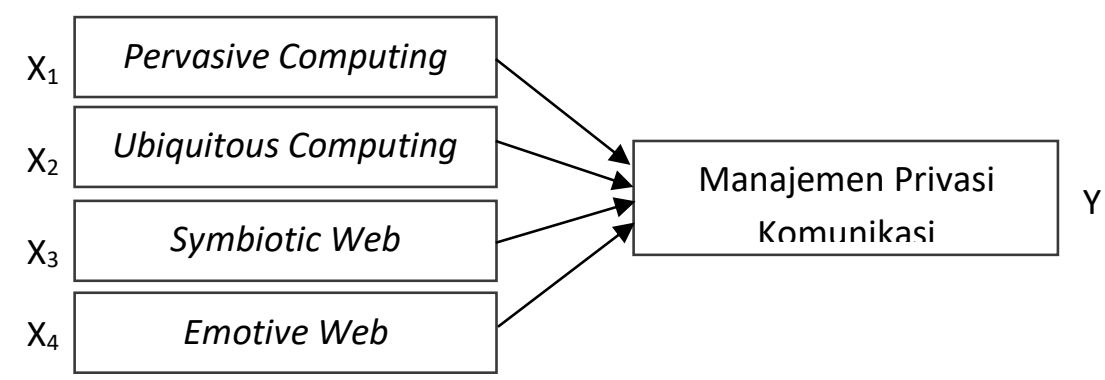

Gambar 1. Kerangka Pemikiran

Sumber Gambar: Hasil olah data penulis

Uji validitas atau mengukur instrumen agar dapat digunakan untuk menghasilkan data valid, penulis menggunakan KMO and Bartlett's test dan signifikan sebesar 0.05. Penulis menggunakan 40 responden awal, dengan isi kuesioner yang terdiri dari 7 pertanyaan $\mathrm{X}_{1}, 6$ pertanyaan $\mathrm{X}_{2}, 7$ pertanyaan $\mathrm{X}_{3}, 7$ pertanyaan $\mathrm{X}_{4}$, dan 12 pertanyaan $\mathrm{Y}$. Dari hasil pengolahan data menunjukan 
bahwa signifikansi dari lima variabel adalah 0.00 atau tidak lebih dari 0.05 , maka variabel ini dianggap layak jadi alat ukur. Untuk melihat alat ukur ini dapat dipercaya dan diandalkan atau uji reliabilitas, penulis menggunakan teknik Alpha Cronbach's karena jenis data kuesioner adalah data interval. Variabel dinyatakan dapat reliabel jika variabel itu lebih dari 0.6. Hasil uji reliabilitas menunjukan kelima variabel dari instrumen ini reliabel dan data terdistribusi normal.

\section{HASIL DAN PEMBAHASAN}

Perkembangan teknologi terus berjalan, seiring berkembangnya media sosial dari web 2.0 menjadi web 4.0. Perilaku manusia pun berubah seiring dengan perubahan lingkungannya. Salah satu perubahan itu adalah keterbukaan informasi privasi akibat perkembangan dari media sosial yang semakin canggih dan kompleks. Kemampuan media sosial berbasis 4.0 mulai dari pervasive computing, ubiquitous computing, symbiotic web, dan emotive web telah mendorong individu untuk membuka informasi privasi, sehingga mempengaruhi manajemen privasi komunikasinya.

Inilah yang menjadi dasar tujuan dari penelitian, untuk melihat konsep dari media sosial berbasis web 4.0 yang paling memengaruhi penggunanya dalam mengelola manajemen privasi komunikasi. Penyebaran kuesioner berlangsung selama 19-21 Mei 2019 melalui penyebaran dari dengan aplikasi Google Form. Dari hasil penyebaran selama tiga hari itu penulis mengambil 324 responden untuk dikaji, dengan identitas responden sebagai berikut: a) responden dengan jenis kelamin laki-laki sebanyak 180 orang $(55.6 \%)$; b) responden perempuan tercatat sebanyak 144 orang $(44.4 \%)$. Berikutnya adalah usia dari responden yang tercantum pada tabel 4.

Tabel 2. Usia Responden

\begin{tabular}{ccc}
\hline Usia (tahun) & Frekuensi & Persentase \\
\hline $17-23$ & 42 & 13.0 \\
\hline $24-31$ & 158 & 48.8 \\
\hline $32-38$ & 74 & 22.8 \\
\hline $39-45$ & 18 & 5.6 \\
\hline $46-52$ & 23 & 7.1 \\
\hline $53-59$ & 9 & 2.3 \\
\hline Total & $\mathbf{3 2 4}$ & $\mathbf{1 0 0}$ \\
\hline
\end{tabular}

Berdasarkan pekerjaan responden, diketahui responden terbanyak, yaitu 119 orang (36.7\%) merupakan karyawan swasta. Selanjutnya, 87 orang (26\%) merupakan pegawai negeri sipil, 19 orang $(5.9 \%)$ pebisnis, dan sebanyak 99 orang $(30.6 \%)$ memiliki pekerjaan lainnya.

Berdasarkan latar belakang pendidikan responden, diketahui responden terbanyak, yaitu 234 orang $(72.2 \%)$ berlatar belakang pendidikan S1. Selanjutnya, terdapat 43 orang (13.3\%) berlatar belakang pendidikan S2, 30 orang (9.3\%) berlatar belakang pendidikan SMA, 13 orang (4\%) berlatar belakang pendidikan D1-D3. Responden paling sedikit berlatar belakang pendidikan SMP sebanyak 2 orang $(0.6 \%)$ dan S3 sebanyak 2 orang $(0.6 \%)$.

Berdasarkan jumlah ponsel yang dimiliki oleh responden, diketahui sebanyak 211 orang (65.1\%) responden memiliki satu ponsel. Sedangkan, responden yang mempunyai dua ponsel terdapat 101 orang $(31.2 \%)$. Sementara responden yang memiliki tiga ponsel atau lebih terdapat 12 orang (3.7\%). 
Pada variabel $\mathrm{X}_{1}$ pernyataan keempat tentang kemudahan mengoperasikan/menggunakan media sosial, sebanyak $45.4 \%$ responden menjawab setuju dan 50,3\% menyatakan sangat setuju. Pada pernyataan keenam terkait media sosial yang dipakai memiliki desain platform (bentuk) yang mendukung fungsinya, sebanyak $52.5 \%$ responden menjawab setuju dan $35.5 \%$ menjawab sangat setuju.

Untuk variabel $\mathrm{X}_{2}$ pernyataan ketiga soal media sosial yang dipakai dapat mengunggah informasi/konten secara otomatis, responden yang menyatakan ragu-ragu sebanyak $23.8 \%$, sementara $29.6 \%$ respons menjawab setuju. Selanjutnya, pernyataan keenam yang menyatakan media sosial yang dipakai mudah terkoneksi dengan aplikasi mendapat respons $48.1 \%$ setuju dan $29.6 \%$ menyatakan sangat setuju.

Pada variabel $\mathrm{X}_{3}$ untuk pernyataan kedua yang menuliskan media sosial yang digunakan menyediakan informasi yang dapat dipercaya, ditemukan responden yang menjawab ragu-ragu sebanyak $49.2 \%$ dan yang menjawab setuju sebanyak $21.3 \%$ responden. Di sisi lain, pada pernyataan ketujuh, media sosial yang digunakan merekomendasikan informasi di kolom jelajah (explore) yang sesuai dengan keperluan, menunjukan sebanyak 50\% responden menjawab setuju, tetapi $23.8 \%$ responden menjawab ragu-ragu.

Melihat pernyataan pertama pada variabel $\mathrm{X}_{4}$, yang menyatakan media sosial yang dipakai memiliki reputasi baik, menghasilkan $51 \%$ responden menjawab setuju, sementara $28.1 \%$ responden menyatakan sangat setuju, dan $17.9 \%$ responden menyatakan ragu-ragu. Pada pernyataan kedua, media sosial yang dipakai aman untuk melakukan/menyelesaikan transaksi (informasi, data, uang, dll) menghasilkan $19.4 \%$ responden tidak setuju, $42.9 \%$ responden raguragu, sementara $21.4 \%$ responden menyatakan setuju.

Pada variabel independen terdapat satu variabel yaitu, manajemen privasi komunikasi. Terdapat 12 pernyataan penelitian dalam variabel ini yang dijawab oleh 324 responden. Pada pernyataan pertama terkait memasukkan data asli saat mendaftarkan diri dalam sebuah media sosial, responden menjawab setuju sebanyak $48.8 \%$, yang setuju sebanyak $29 \%$, sementara yang raguragu sebanyak $14.8 \%$. untuk pernyataan kedua, soal memasukan kontak nomor telepon di akun media sosial, responden menjawab sebanyak $25.3 \%$ tidak setuju, sementara $28.4 \%$ responden lainnya menjawab setuju.

Untuk melihat faktor pada media sosial berbasis web 4.0 sebagai variabel independen atau bebas memberi pengaruh secara parsial pada manajemen privasi komunikasi sebagai variabel dependen atau terikat, maka penelitian ini memakai analisis regresi berganda dan nilai signifikansi sebesar $0.05(5 \%)$. Jika signifikansi memiliki nilai lebih kecil dari nilai 0.05 , variabel independen $\left(\mathrm{X}_{1}, \mathrm{X}_{2}\right.$, $\mathrm{X}_{3}, \mathrm{X}_{4}$ ) secara parsial berpengaruh pada perubahan yang terjadi di variabel dependen (Y) (Ghozali, 2011). Maka untuk melihat angka signifikansi terdapat pada tabel 3. 
Tabel 3. Coefficients ${ }^{a}$

\begin{tabular}{|c|c|c|c|c|c|c|}
\hline \multirow{2}{*}{\multicolumn{2}{|c|}{ Model }} & \multicolumn{2}{|c|}{$\begin{array}{c}\text { Unstandardized } \\
\text { Coefficients }\end{array}$} & \multirow{2}{*}{$\begin{array}{c}\begin{array}{c}\text { Standardized } \\
\text { Coefficients }\end{array} \\
\text { Beta }\end{array}$} & \multirow[b]{2}{*}{$\mathbf{t}$} & \multirow[b]{2}{*}{ Sig. } \\
\hline & & $\mathrm{B}$ & Std. Error & & & \\
\hline \multirow[t]{5}{*}{1} & (Constant) & 11.601 & 3.167 & & 3.663 & .000 \\
\hline & Pervarsive Computing & .310 & .112 & .160 & 2.770 & .006 \\
\hline & Ubiquitous Computing & .193 & .098 & .108 & 1.972 & .049 \\
\hline & Symbiotic Web & .290 & .108 & .181 & 2.683 & .008 \\
\hline & Emotive Web & .334 & .127 & .181 & 2.620 & .009 \\
\hline
\end{tabular}

a. Dependent Variable: Manajemen Privasi Komunikasi

Tabel 3 menunjukan bahwa keempat variabel tersebut berpengaruh terhadap manajemen privasi komunikasi. Variabel $\mathrm{X}_{4}$ emotive web memiliki pengaruh terbesar terhadap variabel dependen, dengan ukuran koefisien Beta sebesar $33.4 \%$. Variabel $\mathrm{X}_{1}$, pervasive computing, memberikan pengaruh sebesar $31 \%$. Selanjutnya, variabel $\mathrm{X}_{3}$, symbiotic web memberikan pengaruh sebesar $29 \%$, dan variabel $\mathrm{X}_{2}$, ubiquitous computing menyumbang pengaruh sebesar $19.3 \%$.

Nilai korelasi atas variabel $\mathrm{X}_{1}, \mathrm{X}_{2}, \mathrm{X}_{3}$, dan $\mathrm{X}_{4}$ secara simultan terhadap variabel $\mathrm{Y}$ adalah sebesar 0.232. Jika dilihat berdasarkan koefisien korelasi, nilai korelasi antara variabel independen dengan dependen adalah rendah.

Nilai sumbangan efektif setelah diolah dengan menggunakan rumus sumbangan efektif dan sumbangan relatif berdasarkan hasil dari pengolahan data SPSS (Widhiarso, 2001). Dapat dilihat bahwa, variabel pervasive computing $\left(\mathrm{X}_{1}\right)$ memiliki nilai 5,568 dari pengaruh nilai korelasi pada manajemen privasi komunikasi. Untuk variabel ubiquitous computing $\left(\mathrm{X}_{2}\right)$ memiliki nilai 3,089 terhadap pengaruh nilai korelasi pada manajemen privasi komunikasi. Selanjutnya symbiotic web $\left(\mathrm{X}_{3}\right)$ memiliki nilai 7,186 terhadap pengaruh nilai korelasi pada manajemen privasi komunikasi. Untuk emotive web $\left(\mathrm{X}_{4}\right)$ memiliki nilai 7,331 terhadap nilai korelasi pada manajemen privasi komunikasi. Jumlah dari seluruh sumbangan efektif memiliki nilai yang sama dengan $R$ Square yaitu 23,2.

Sementara untuk sumbangan relatif, melihat besaran ukuran yang disumbang oleh variabel indepen terhadap jumlah kuadrat regresi. Dari hasil data pada tabel 11, maka dapat dijabarkan sebagai berikut. Variabel pervasive computing $\left(\mathrm{X}_{1}\right)$ memiliki nilai $24 \%$, sementara variabel ubiquitous computing $\left(\mathrm{X}_{2}\right)$ mempunyai nilai $13 \%$, selanjutnya symbiotic web $\left(\mathrm{X}_{3}\right)$ bernilai $31 \%$, dan emotive web $\left(\mathrm{X}_{4}\right)$ memiliki nilai $31 \%$. Jika nilai sumbangan relatif dijumlah maka nilainya adalah $100 \%$ atau 1.

\section{KESIMPULAN DAN SARAN}

Dari hasil penelitian dapat ditemukan bahwa ada pengaruh yang signifikan antara media sosial berbasis web 4.0 terhadap manajemen privasi komunikasi. Sehingga dapat disimpulkan bahwa media sosial berbasis web 4.0 akan mempengaruhi manajemen privasi komunikasi penggunanya, seperti penyajian data pribadi di aplikasi media sosial yang digunakan. Dari empat konsep yang diajukan dalam web 4.0, konsep emotive web menjadi variabel yang paling berpengaruh terhadap manajemen privasi komunikasi, baik secara parsial maupun simultan, dibandingkan dengan konsep lainnya, pervasive computing, symbiotic web, dan ubiquitous computing. Namun, keempat konsep web 4.0 tetapi memberikan signifikansi perubahan terhadap manajemen privasi komunikasi. Penulis menyimpulkan semakin berkembangnya hubungan antara manusia dan mesin, akan membuat manusia untuk lebih terbuka terkait data pribadinya. Mesin yang bekerja 
untuk memenuhi kebutuhan penggunanya tentu memerlukan data yang harus diolah agar rekomendasi yang diberikan sesuai keinginan pengguna, bahkan dapat mempengaruhi perilaku pengguna. Sehingga, pada perkembangan ke depan, saat web 4.0 semakin disempurnakan dan munculnya web 5.0, mesin tidak lagi menunggu konfirmasi pengguna untuk bekerja, tetapi sudah mampu membaca perilaku dan kebiasaan pengguna dari pola konsumsi di media digital, salah satunya media sosial.

Untuk penelitian selanjutnya dapat memfokuskan pada pemilihan responden dengan sampel probabilitas, sehingga dapat secara jelas merepresentasikan sebuah populasi, baik dari pola konsumsi media sosial atau berdasarkan demografis tertentu. Menambahkan variabel lain yang memiliki pengaruh yang kuat dibandingkan konsep emotive web. Selain itu, kesadaran pengguna media sosial harus diperdalam, karena dapat dipengaruhi oleh faktor dan motivasi lainnya. Seperti pada hasil responden yang menilai bahwa reputasi media sosial yang digunakan itu dinyatakan baik, tetapi ada keraguan dari responden terkait informasi yang diberikan oleh media sosial.

\section{Ucapan Terima Kasih (Acknowledgement)}

Penulis hendak menyampaikan ucapan terima kasih kepada sejumlah pihak yang telah membantu dalam penelitian ini, para responden yang telah meluangkan waktunya untuk mengisi dan ikut menyebarkan kuesioner ini serta pengajar mata kuliah Perspektif Industri Teknologi Komunikasi.

\section{REFERENSI}

Aghaei, S., Nematbakhsh, M. A., \& Farsani, H. K. (2012). Evolution of the world wide web: From web 1.0 to web 4.0. International Journal of Web \& Semantic Technology, 3(1), 1-10. http://airccse.org/journal/ijwest/papers/3112ijwest01.pdf

Almeida, F. L. (2018). Concept and dimensions of web 4.0. International Journal of Computers \& Technology, 16(7), 7040-7046. https://doi.org/10.24297/ijct.v16i7.6446

Artaza, D. L. de I. G. de. (2012). Web 2.0, future internet, semantic web and ubiquitous web. Library Technology Reports, (2002), 10-14.

Barnard-Wills, D., \& Ashenden, D. (2015). Playing with privacy: Games for education and communication in the politics of online privacy. Political Studies, 63(1), 142-160. https://doi.org/10.1111/1467-9248.12049

Barnes, S. J., \& Vidgen, R. (2003). Measuring web site quality improvements: A case study of the forum on strategic management knowledge exchange. Industrial Management and Data Systems, 103(5), 297-309. https://doi.org/10.1108/02635570310477352

BBC. (2014). Instagram menghapus jutaan akun sampah. BBC News Indonesia. https://www.bbc.com/indonesia/majalah/2014/12/141219_iptek_instagram

Benito-Osorio, D., Peris-Ortiz, M., Armengot, C. R., \& Colino, A. (2013). Web 5.0: The future of emotional competences in higher education. Global Business Perspectives, 1(3), 274-287. https://doi.org/10.1007/s40196-013-0016-5

Bhasker, T, L. (2013). Pervasive computing issues, challenges and applications. International Journal of Engineering And Computer Science, 2(12), 3337-3339. http://www.ijecs.in/issue/v2-i12/1 ijecs.pdf

Choudhury, N. (2014). World wide web and its journey from web 1.0 to web 4.0. (IJCSIT) International Journal of Computer Science and Information Technologies, 5(6), 80968100. https://doi.org/10.1186/1471-2105-9-82

Ghozali, I. (2011). Aplikasi analisis multivariate dengan program SPSS. BP Universitas Diponegoro. 
Kirik, A. M., Ahmet, A., Çetunkaya, A., \& Gül, M. (2015). A quantitative research on the level of social media addiction among young people in Turkey. International Journal of Science Culture and Sport, 3(3), 108-122. https://doi.org/10.14486/ijscs444

Krumova, M., Paunova, L., \& Yotova, S. (2017). Open and linked data in business: Disruptive marketing mix 3.0. Journal of Management and Innovation, 3(1), 1-19. https://doi.org/10.18059/jmi.v3i1.31

Kurgun, H., Kurgun, O. A., \& Aktaş, E. (2018). What does web 4.0 promise for tourism ecosystem? a qualitative research on tourism ecosystem stakeholders' awareness. Journal of Tourism and Hospitality Management, 6(1), 55-65. https://doi.org/10.15640/jthm.v6n1a6

Martínez-López, F. J., Anaya-Sánchez, R., Aguilar-Illescas, R., \& Molinillo, S. (2016). Online brand communities: Using the social web for branding and marketing. Springer International Publisher. https://doi.org/10.1007/978-3-319-24826-4

Moor, J. H. (1997). Towards a theory of privacy in the information age. Computers and Society, 27(3), 27-32. https://doi.org/10.1145/270858.270866

Mulawarman, M., \& Nurfitri, A. D. (2017). Perilaku pengguna media sosial beserta implikasinya ditinjau dari perspektif psikologi sosial terapan. Buletin Psikologi, 25(1), 36-44. https://doi.org/10.22146/buletinpsikologi.22759

Nath, K., \& Iswary, R. (2015). What comes after web 3.0? web 4.0 and future. International Conference on Computing and Communication Systems (I3CS'15), 337-341.

Nedeva, V., \& Dineva, S. (2012). New learning innovations with Web 4.0. The 7th International Conference on Virtual Learning ICVL.

Neuman, W. L. (2014). Social Research Methods Qualitative and Quantitative Approaches, 7th Edition. Pearson Education Limited.

Nisha, J. R., \& Education, A. C. V. O. C. (2018). Evolution of education: Towards sensory emotive web. International Journal of Science, Engineering and Management, 3(4), 655-658.

Ocampo, L. A. R. (2017). How to Communicate in the Age of Web 4.0?: Challenges and possibilities for religions in asia. Religion and Social Communication, 106-121.

Patel, K. (2013). Incremental journey for world wide web: Introduced with web 1.0 to recent web 5.0 - a survey paper. International Journal of Advanced Research in Computer Science and Software Engineering, 3(10), 410-417.

Patil, H. J., \& Surwade, Y. P. (2018). Web technologies from web 2.0 to web 4.0. International Journal for Science and Advance Research In Technology, 4(4), 810-814. https://doi.org/10.4018/978-1-60566-788-1.ch002

Petersons, A., \& Khalimzoda, I. (2016). Communication privacy management of students in Latvia. Problems and Perspectives in Management, 14(2). https://doi.org/10.21511/ppm.14(2-1).2016.11

Petronio, S. (2016). Communication privacy management theory. The International Encyclopedia of Interpersonal Communication, 1 st Edition, 1-9. https://doi.org/10.1080/15267431.2013.743426

Polańska, K. (2014). Social media in modern business. European Scientific Journal, 1, 335-345.

Sastika, W. (2016). Analisis pengaruh kualitas website (webqual 4.0) terhadap keputusan pembelian pada website e-commerce Traveloka. Sentika, 2016, 18-19.

Sugiyono. (2013). Metode Penelitian Kuantitatif, Kualitatif, dan R\&D. Alfabeta CV.

Tuunainen, V. K., Pitkänen, O., \& Hovi, M. (2009). Users' awareness of privacy on online social networking sites - case facebook. 22nd Bled EConference EEnablement: Facilitating an Open, Effective and Representative ESociety. 
Wardani, A. S. (2019). Awal 2019, facebook sudah hapus 753,7 juta akun palsu. Liputan6.com. https://www.liputan6.com/tekno/read/3876641/awal-2019-facebook-sudah-hapus-7537juta-akun-palsu

We are Social. (2019). Digital 2019: Global internet use accelerates. https://wearesocial.com/blog/2019/01/digital-2019-global-internet-use-accelerates

Weber, S., \& Rech, J. (2010). An Overview and differentiation of the evolutionary steps of the web x.y movement. Handbook of Research on Web 2.0, 3.0, and X.0, 12-39. https://doi.org/10.4018/978-1-60566-384-5.ch002

Widhiarso, W. (2001). Menghitung sumbangan efektif tiap aspek terhadap variabel dependen. Fakultas Psikologi UGM. 